\title{
Investigating Commercial Capabilities and Trust in Social Media Applications for Entrepreneurs
}

\author{
Aisha Ahmed AlArfaj ${ }^{1,2}$ \\ aiaalarfaj@pnu.edu.sa
}

\author{
Ellis Solaiman ${ }^{1}$ \\ ellis.solaiman@ncl.ac.uk
}

\author{
${ }^{1}$ School of Computing, Newcastle University, Newcastle Upon Tyne, UK \\ ${ }^{2}$ College of Computer and Information Sciences, Princess Nourah bint Abdulrahman University, Riyadh, Saudi Arabia.
}

\begin{abstract}
This study attempts to present sellers' behaviours and activities in social commerce within the context of a local social group. It describes how the sale and marketing of homemade products, or imported goods, are conducted in Saudi Arabia using social media platforms (Instagram, WhatsApp, Twitter, and Snapchat) as well as using offline tools such as phones, family and friend recommendations, and events. We interviewed 17 female entrepreneurs who own e-shops on social media applications. The research describes how sellers try to market themselves and build their reputation to gain consumer trust despite a lack of commercial functionality within the social platforms that they use. This paper presents insights into new opportunities for peers and business owners that social commerce can bring. We also argue that social media applications can expand their uptake from businesses and entrepreneurs by designing functionality aimed at improving their commercial capabilities, and aimed at enabling sellers to build their own reputation and trust.
\end{abstract}

\section{CCS CONCEPTS}

- CCS $\rightarrow$ Human-centered computing $\rightarrow$ Human computer interaction $(\mathrm{HCI}) \rightarrow$ Interaction techniques

\section{KEYWORDS}

Social commerce, social media, trust, Instagram, social networking

\section{ACM Reference format:}

Aisha Ahmed AlArfaj and Ellis Solaiman. 2019. Investigating Commercial Capabilities and Trust in Social Media Applications for Entrepreneurs. In Proceedings of ACM C\&T conference (C\&T'19). ACM, Vienna, Austria, 11 pages. https://doi.org/10.1145/3328320.3328390

Permission to make digital or hard copies of all or part of this work for personal or classroom use is granted without fee provided that copies are not made or distributed for profit or commercial advantage and that copies bear this notice and the full citation on the first page. Copyrights for components of this work owned by others than ACM must be honored. Abstracting with credit is permitted. To copy otherwise, or republish, to post on servers or to redistribute to lists, requires prior specific permission and/or a fee. Request permissions from Permissions@acm.org.

C\&T 2019, June 3-7, 2019, Vienna, Austria

(C) 2019 Association for Computing Machinery.

ACM ISBN 978-1-4503-7162-9/19/06 ..\$15.00

https://doi.org/10.1145/3328320.3328390

\section{Introduction}

Social media applications have received substantial attention in the HCI community [17][2][42][12]. Firms of all sizes report a rapid increase in using social media for commercial activities [21][22]. There is also a shift in the way of dealing with commercial activities. E-commerce is largely a one-way activity; however, recently, Web 2.0 technologies have enabled bidirectional communication between sellers and buyers [4]. The emergence of Web 2.0 has created business opportunities for micro-entrepreneurs who wish to promote their products, reach people, and build their reputation [47]. The use of Web 2.0 technologies, such as social media platforms for commercial activities is known as social commerce [9]. The adoption of social media for commerce and communication has been an important research topic [50], with many researchers conducting studies within the context of particular social groups around the world [47][20]. The focus of this study is on the adoption of social commerce within the country of Saudi Arabia where social media plays a significant role in the everyday lives of people as they are considered a collectivistic culture that gives family and social groups a high value [2].

Amongst Researchers, Social Commerce has recently become a hot topic. As a discipline, it is still in its infancy and conducted mainly in Western countries, where consumer behaviour may not necessarily be cross-cultural [41]. A few introductory studies have focused on social commerce activities from the sellers' perspective and social media design [40][14][42]. This paper aims to explore the motivational factors needed to start a business using social commerce platforms, and the effect of social media design on consumers to fill this demand. Additionally, the paper investigates how they gain consumer trust and how they trust their consumers. The research discusses how selling products may succeed on platforms that lack traditional commercial tools and how the sellers are building their reputations.

The research questions for this paper are: 1) why do sellers choose to open a business, especially on social networks? 2) How are entrepreneurs using social media in conducting commercial activities? 3) How are entrepreneurs gaining consumers trust? To answer these questions, qualitative data was collected through interviews. 
In summary, our paper makes the following contributions:

- Understand the motivations to open a business, especially on social media platforms.

- $\quad$ Provides an understanding of how sales work through social media platforms in Saudi Arabia.

- Investigates seller practices and customer activities that may affect trust.

- Our findings contribute to the growing body of research on social commerce and social media.

- Based on our findings, the research discusses design considerations that may enhance trust in social commerce platforms to improve the user experience.

This study was conducted in Saudi Arabia, and investigates Saudi entrepreneurs' use of social media applications. Currently, the Saudi government has established a 2030 vision, and one of the intended commitments is to support entrepreneurs and help them to export their products and services by enhancing e-commerce [3]. Riyadh chamber, under the Saudi government sector, organises a free, yearly event for Saudi entrepreneurs to display their products. In 2017, they received more than 1000 applications to participate in the exhibition, and they accepted around 600 female entrepreneurs [52]. The first author had attended two of these events and found that the main, and sometimes the only, way to display their product is by using social media applications, mainly, Instagram, WhatsApp and Snapchat. The government has also established an initiative called 'Maroof', which provides businesses and entrepreneurs with a free service which certifies their businesses to enhance trust between sellers and buyers [39]. To register in Maroof, one needs to use his/her Saudi ID, which is similar to other schemes in places such as China [24]. Within Saudi Arabia, the leading business social media platforms are Facebook, LinkedIn, YouTube, Twitter, Instagram, Pinterest and Snapchat [38]. Support from the government and from social media applications has empowered women and given them opportunities to succeed in their respective businesses.

\section{Related Work}

Social commerce is a new era of e-commerce that utilises web 2.0 to encourage users to socialise while shopping by using social media applications to conduct commercial activities [9]. Social media applications have been used by small businesses (entrepreneurs) due to the potential benefits for both sellers' and buyers' perspectives [4][27][32]. These motivations, which we will elaborate on further, can be categorised as advertising, building reputation, customer interactions (with sellers and their feedback), networking, and self-esteem. These motivations can have an effect on the consumer trust, which is crucial in order to have a successful commercial peer-to-peer exchange process [29]. Social media applications provide sellers with opportunities to advertise [4]. For example, applications such as Facebook, Twitter and Instagram, allow users to advertise e-commerce websites on their platforms by adding hyperlinks to enable consumers to complete transactions [50] or by promoting particular posts to reach more people [25]. Therefore, they help sellers in finding new customers, creating a network, and increasing sales [27].
Entrepreneurs have also used social media applications to build social capital by presenting themselves and connecting to others [14]. This can be done by using social features that help in developing trust, such as having followers [9][15]. Furthermore, the communication between sellers and buyers may provide the customer with more information that they require to make an informed decision [19]. This can also help in building relationships with new customers, strengthening ties with existing ones, and building trust [27]. The degree of closeness and strength of the relationship between the service provider and the customer is known as 'relationship quality', a significant contributor to customer loyalty [34].

Some of the social commerce platforms provide sellers with features that help them build their reputation [27] [32]. A good reputation can be considered a form of social capital, which enables them to know further details such as location, interest, social activities, and friends [1]. For example, Airbnb and Couchsurfing include profiles as well as reviews and ratings by others within the service providers' profiles [29][15], to help in establishing online social presence [17] and trustworthiness [37], which contribute towards attracting more users [33]. Previous customer reviews are more informative and allow the consumer to gauge the trustworthiness of the account [29]. The warranting theory states that pieces of information that are hard to manipulate are more helpful for consumers to evaluate the trustworthiness of a seller [44]. For example, actual photos from previous customers are more difficult for a seller to fabricate than the description of a product.

An important part of social commerce are the features which aid customer interactions such as having user-generated content and information sharing capabilities [9][50][32]. Customer feedback can assist sellers to ascertain which products or services they need to improve [32]. For example, on Facebook, features such as 'Likes', 'shares', 'tags', and comments from friends aid customer interactions [45]. Social commerce can aid with improving trust between sellers and buyers where existing peer connections exist [46][41]. This is evident within family and friend peer groups, where there exists a natural relationship of trust. Within such groups, users find it easy to trust recommended products and services. This trust may also extend to friends-of-friends (FOF) networks [46][8]. For example, in Venezuela, users check the Facebook member list of the seller and see if there are friends in common that they can trust in order to complete a trade [12].

Because of the benefits discussed above and others, businesses are increasingly adopting social commerce and integrating social features into their online presence through social media platforms like Facebook and Twitter [18]. This enables a network of followers, and helps sellers promote and attract others to buy from them [18]. Furthermore, the interactions that sellers have with their customers through social media can have a significant impact on sellers' self-esteem, especially when a relationship of trust is established, and interactions with customers are positive [22], in addition to their entertainment value [27]. Interestingly, some social media applications have recently incorporated new features to enable business transactions. For example Facebook and Instagram have added the 'shop now' button [13]. 
Table 1 Information about the participants

\begin{tabular}{|c|c|c|c|c|c|c|c|}
\hline$\#$ & age & Status & education & Job & $\begin{array}{l}\text { Number of } \\
\text { Followers }\end{array}$ & Products they sell & $\begin{array}{l}\text { Have a } \\
\text { website }\end{array}$ \\
\hline P1 & $19-24$ & Single & bachelor & none & 3095 & Gifts/ accessories & No \\
\hline P2 & $25-34$ & Married & bachelor & none & 2115 & Perfume & No \\
\hline P3 & $25-34$ & Married & bachelor & none & 1032 & Design (logo/ advertisement) & No \\
\hline $\mathrm{P} 4$ & $25-34$ & Married & bachelor & none & 923 & Gifts & No \\
\hline P5 & $19-24$ & Single & high school & student & 1665 & Perfume & No \\
\hline P6 & $25-34$ & Single & bachelor & teacher & 972 & Drawing/gifts & No \\
\hline P7 & $45-54$ & Married & bachelor & retired & 3796 & Gifts & No \\
\hline P8 & $25-34$ & Single & bachelor & none & 574 & Gifts & No \\
\hline P9 & $25-34$ & Married & bachelor & none & 5255 & Party gifts/ cards & Yes \\
\hline P10 & $25-34$ & Married & high school & none & 11,200 & Soap & No \\
\hline P11 & $35-44$ & Divorced & bachelor & none & 17,300 & Sweets & No \\
\hline P12 & $35-44$ & Married & high school & none & 2876 & Soap & No \\
\hline P13 & $19-24$ & Single & high school & student & 9786 & Perfume & No \\
\hline P14 & $35-44$ & married & bachelor & none & 3118 & Coffee & No \\
\hline P15 & $25-34$ & single & postgraduate & none & 9243 & Accessories & No \\
\hline P16 & $25-34$ & single & diploma & none & 19,718 & Food & No \\
\hline P17 & $25-34$ & married & bachelor & none & 6057 & Games and toys & No \\
\hline
\end{tabular}

There are few studies which examine the use of social media for conducting commerce from the point of view of sellers and their businesses [45][31]. This paper will focus on how entrepreneurs use social media to conduct their business activities, and provide insights into their experiences and the methods by which they maximise the benefits and unique features of social media applications. We will also find out from entrepreneurs how they would like to see social commerce applications evolve in order to support their activities.

\section{Method}

Our research aims to provide an understanding of the business use of social media applications. To answer the research questions listed in the Introduction, ethnographic studies were conducted in Saudi Arabia in order to explore and understand entrepreneurs' behaviours and routines on using social media platforms. The data was collected from December 2017 to December 2018. For the purposes of our study, in order to gain a detailed understanding of the users, it is recommended to interview at least 12 participants [5]. We, therefore, conducted in-depth semistructured interviews (face-to-face and online) with 17 participants (ten face-to-face interviews, and seven online interviews) with Saudi women who have social media accounts to display their products. Table 1 presents information about the participants.

Participants were recruited using two different ways. The first was by attending an event for home-based businesses and distributing our study information sheet with a consent form to sellers who use social media networks as a market place to present their products. Then, after around half-an-hour they were approached to find out if they are willing to participate in our study by filling the consent form. The second way was by sending an online sign-up form with our study information sheet and the consent form through social media platforms by using personal messages via instant messages in Instagram and WhatsApp. Once they filled the consent form, they were contacted to conduct the interviews. Interviews were conducted in Arabic and took around 30 minutes. Participants were compensated with a \$15 gift card; however, many participants rejected the compensation and opted to take part in the study voluntarily.

The interviews were transcribed in the original language from the audio recordings. Our research followed a thematic analysis using the inductive approach [7]. The inductive approach is an effective way to research an area such as ours in which few previous studies have been conducted [6]. The transcripts were coded using ATLAS.ti. ATLAS.ti is a data analysis software that helps to deal with qualitative data especially for the Arabic language. It allows to code the data and to organise these codes under categories. Two types of coding were followed, open coding and axial coding, as mentioned by Saldana [43]. Examples of codes when participants were asked how they gain consumers trust: "sellers registered in Maroof", "asked family and friends", etc. The codes were grouped into categories such as sellers' practices and customer activities.

\section{Findings}

The findings first describe the motivations that drive participants to start a business as well as the reasons behind using social media applications as business platforms. Then, buyer and seller practices and activities are reported on the theme of trust.

\subsection{Motivations}

Participants became sellers because of a variety of motives and reasons which are mostly under one of these categories: family and friends, government, self-motivation, and social media. The participants were mainly motivated to start their business by their family and friends. Fifteen participants reported that their family supported and helped them in different ways, such as managing their business on social media applications, recommending them to others, and provided emotional and financial support. 
Seven participants have members of their family or friends working with them. They own and run the business together. For example, some of the participants are working with their sisters (P1) (P4), or with their mothers (P2) (P5) (P7) or sons (P13), or with a friend (P10). They feel it is better to have someone, especially from their circle of friends or family members, to help them with their business in answering the consumers' questions, taking the orders, and managing their accounts on social media platforms. For example, all of these people will have their Instagram accounts open in the seller's mobile and his/her partner's mobile, and the twitter account and snapchat under the responsibility of the seller, whereas the WhatsApp account will be under the responsibility of the partner. The reason behind having a partner is to avoid a delay in answering consumer questions and receiving the orders, as well as to remain active in these accounts. We run our accounts together, me and my sister and my friend. It is good because the one who is free can answer the questions, so it is more convenient to have more than one person. This way, the consumers will not stay for a long time without a response. (P10)

Conversely, six of the participants stated that they run their business and accounts on their own. They were going to make the order by themselves. Therefore, they need to take orders and answer the questions by themselves in order to fully understand consumer needs and requirements. I took the orders because I am the one who is going to draw the picture, so I need to understand what the consumer wants directly. (P8)

They also obtain support from their family through recommendations to their friends and other people they know, which will be mentioned later in the trust section. In addition, the participants expressed that they obtained emotional support from their family and friends, such as the encouragement to convince them to try and start a business. My family supported and encouraged me to start a business since they really love the sweets that I have made. (P11)

Therefore, some participants began by offering their products to some of their extended family members (such as aunts) as well as their friends and friends of friends. When they found that their products are accepted and reordered, they decided to start their businesses. We began the business with our relatives when they had a party; we gave them some of our products inside a surprise box, and when we saw that they liked and enjoyed it, we decided to start our business. (P6)

Four more participants said that cultural changes, plus the government's 2030 vision gave them the opportunity to succeed, especially since the community began to change its mindset and came to terms with seeing women working in public spaces, and owning businesses. After my father has seen what I have done and how I have succeeded in my business, he is proud of me.(P14). Eleven participants reported that support from the government plays a significant role in motivating them to start online businesses. The government provided more support to entrepreneurs by providing them with three main components; Maroof (free business certification service), 9/10th (an e-commerce platform), training courses and Montijoon (an exhibition for entrepreneurs). I went to the Riyadh Chamber of Commerce where they told me that they had an event called Montijoon in which I could participate. They also told me that there were a few workshops during the event that can help me to develop my business. (P14). These changes motivate the participants to use their skills to open a business and use their time positively for a sense of satisfaction and for an income, especially since all but two participants reported that they did not have a job. They also enhance their skills by attending workshops or training courses to present their business in the best way. I love drawing and arts. It is my hobby, and I was searching for the materials that I could use. I also improve my skills by attending drawing courses.(P8).

One of the participants (P12) stated that she was following a snapchat account which gave ideas for the home. One day they made a bath bomb, which she liked and tried to recreate. She also reported that after contacting the snapper, she felt motivated to work harder and to open a business.

The participants mentioned that they needed something that could help them have a social presence and social interaction, both of which was found in social media applications. Their motivation to establish their business in social networks was mainly owing to the network people, its easy-use, the fact that it was free, and its design and presentation.

The participants stated that Instagram and WhatsApp are the most popular social media applications in Saudi Arabia, especially for business. For this reason, they choose them to reach people and be able to contact new customers. Thirteen participants felt that it helps them to have social engagement (social exchange). Nine of them mentioned that they love to have public relations and build relationships with their customers. Few participants $(n=3)$ reported that they could now say that they are successful entrepreneurs. All these things lead the participants to feel more confident and have greater self-esteem. I choose to use Instagram because it is one of the most popular social media applications in Saudi Arabia. (P10)

One of the participants (P13) had a son who was diagnosed with cancer. She decided to open a business to keep him occupied with an activity that he could do from home and could succeed in at the same time. In addition, she felt that the business might help in his therapy by providing him with hope and greater self-esteem, which would help him succeed.

The existence of social media is one of the motivations to have a business. Thirteen of the participants found that it is easy to use social media applications, which could be accessed anytime and from anywhere. Moreover, four of the participants indicated that they were motivated to use social media, because it was free of cost and did not require them to pay anything, instead of opening a physical shop or developing a costly e-commerce website. Three of the participants said that they choose Instagram as it is a photo and video-based application which presents them as a catalogue and this makes it easier for consumers to view the products. I used Instagram as I can post my product and write about it under the post. Also, it is easy to use and to receive direct messages and to reach people. (P2)

\subsection{Trust}

Several factors help sellers to be known and trusted, which include family and friends' recommendations, customers' 
interactions, and sellers' practices. The practices of friends and family, previous customers and sellers help in building trust between sellers and buyers.

\subsubsection{Family and friends' recommendations}

Family and friends were one of the first and most common sources that were known and trusted. It is like the first phase of being recognised and starting the business. The sellers' friends and family members will try to recommend them to other members of their family and friends. Ten of the participants believed that people know them from their friends and family as they share their accounts in WhatsApp groups. These groups in WhatsApp usually have their friends, family, and colleagues at work. Sellers think that this may attract people to know their account and to trust them, as they know them from someone they believe and trust. I sent my business account to my friends and to all the WhatsApp groups that I have. My sisters also did the same. (P7).

Ten of the participants mentioned that their family, relatives and friends made their accounts known offline, by taking samples to their work or by telling their friends about their account. My aunt took some of my products to her work to show her colleagues. (P2)

\subsubsection{Customers' interactions}

Most of the participants $(n=13)$ believed that it is not only their family and friends who help them to be known, but also previous customers who play a significant role. Customer interactions can be divided into offline and online communications. First of all, participants mentioned that consumers might tell their family and friends and this is also a way to be known and trusted. They might tell their friends and family in person. They also may initiate their family and friends into trying the product at home. In addition, the sellers indicated that if they are going to buy something, they would ask their family and friends. When I need to buy something, I asked my family and friends from where I should buy the product that I need, and when they recommend a seller account, I buy from this account directly. Then, I told the seller that my friends or family recommended her/him because I think it may help the seller to be more confident and feel supported. (P11)

Furthermore, consumers may post a picture of the product in their Snapchat. If their family or friends ask them about the product, they will give them more details. They also may send directly to their friends or family a picture of the product when they know that their family or friends are looking for this product. Also, they may send a product they tried and liked to their friends, in order to have them share the experience. One of the participants said that a lot of consumers told her that they knew her from their cousins or friends. Most of my customers are from previous customers. For example, when I have a delivery for the product, from the second day, I will have one or two more followers who even place some orders, and I think they are friends or family of the one who received the product. (P13)

Moreover, customers also play a significant role to help sellers keep their account active, which impacts on the trust and help them be known. Having an active account needs both seller and customer interactions. The seller's side will be covered in the next section. From the customer's side, the account can be active by having social engagements from previous and potential customers, which may help in gaining trust through 'likes', views, tags, mentions, and comments.

Four participants reported that 'likes' might attract other consumers and give them confidence. However, two participants noticed that people currently stop 'liking' photos as much as before and simply view them and continue browsing. They did not know the reasons behind this. In the last two years people started to use Instagram just for viewing and without liking the posts as before. (P5)

Three participants stated that the viewer numbers under the video posts helps to show that their accounts are widely-viewed. It is also much more than the like numbers as views are automatically counted. Views are sometimes from people who do not follow the account as well. I have many of views which work as silent marketing even without being followed. (P14)

Participants $(n=15)$ reported that they use the tag or get tagged or mentioned by others. Tag and mentions help sellers to be known and sometimes to be trusted. Friends mention their friends under the sellers' posts, which may let others and the friend trust this seller, or post a photo of the product in their Instagram account with a tag to the seller' account. However, the number of tags may not be a lot; this is quite a rare occurrence. Tags are really helpful to enhance trust when a customer takes a photo of my product and tags me. However, there are not a lot of customers who did that. Most of the tags are from advertisement accounts. (P13)

Most of the participants $(n=14)$ said that they receive comments from previous and potential consumers. These comments may include queries such as questions asking for more details about the product, delivery or price. It also could be positive comments about the product and that he/she liked this product. Consumers sometimes leave positive comments without writing anything, such as an emoji like the smile face or flowers. Participants think that these comments are critical as it is easier and faster for consumers to ask for more details than by sending WhatsApp messages. In addition, these comments give confidence to other consumers that they should trust the seller as the answers are public. It is also important for sellers as they get to know what consumers prefer more, and what they need to improve on. The comments are critical as consumers will see that there are people who are buying and writing comments for you and thus, they will trust you. (P7)

Some participants $(n=7)$ stated that these comments are rare and quite few. They also believe that the number of comments is becoming less than before. Comments are valuable and can enhance trust, but it is rare. However, it is perfect for us as it attracts potential consumers and lets them trust us. (P13)

However, several participants $(n=8)$ reported that they rarely get negative comments. These comments may talk about a high price, or that they did not like a product. However, four participants mentioned that they never received a negative comment. Almost all participants agreed that if they received negative feedback, it may affect their reputation, and then they will delete the comments to protect their reputation. Few participants stated that they would not remove that negative comment if it was just about the price or if it was written properly. When I receive comments 
about my price and that my products are expensive, then I ignore it and try to produce a better product to show them that it was worth the price. (P8)

\subsubsection{Sellers' practices}

Certain seller activities can enhance trust with the aid of technology. First, technology can help them build their reputations by having a profile (as a shop window), establishing interpersonal interaction, advertising, having themselves certified by Maroof, having a website, registering in e-commerce platforms, and attending events. Furthermore, the payment and delivery options can also effect trust.

\subsubsection{Social media features}

Participants find that some social media features can help them in their businesses to build their reputation, starting from having a profile for their account, which is one of the most important things as it is a window to their e-shop. It includes important and general details, such as payment and delivery methods. It includes ways of contact such as their mobile or WhatsApp numbers. I have included the essential details in my profile, such as prices, delivery method and the way of payment, to help consumers find what they need. (P1)

Participants believe that the profile has a vital role in trust, especially when it has more details and more information. For example, if it contains business information including the location, they will gain more consumer trust. The profile can effect consumer trust if I have all my details in my profile with my phone number, making it easier for the consumers. I know that a few people wish to contact me directly to feel more confident. (P3). They feel that their profile is the shop window, where consumers judge if they can trust them. The profile includes the bio that the sellers will write, the follower numbers, and post numbers as well as the posts themselves. The participants felt that the follower numbers had a significant effect on trust. They believed that having a lot of followers gave the consumers the feeling that the sellers are trustworthy. To increase follower number, sellers tend to have a public account and to advertise their account. The number of followers is really important for the consumers as the more the number of followers, the more the confidence and trust they have in the seller. (P16)

Not all the participants wrote their name in their shop profile. Some of them $(n=11)$ think that it is not essential to include their name. However, if consumers ask them or are about to transfer money to them, they will give them their names. Six participants did not prefer to relate their business to their names, but they prefer to have a brand name and know their business by this brand name, which they think is more professional. It is also because they were afraid that in case they failed, people would possibly relate their name to a failed business. I do not like to add my name to my profile as my name is not unique; however, my brand name is. (P11)

All the sellers but one, made their account public, which means that anybody could see it as they believe it gives them a chance to have more followers and makes them more accessible to their customers to view their profile anytime and without having a need to wait till the sellers accept them. A few consumers hate to see a private account; then you will lose these consumers. Therefore, it is better to have it public. (P1)

However, one of the participants chose to set her account private, mostly because she felt that this might attract people more to add her to see what she has as products and to protect her posts from being stolen by others. The stealing of posts and ideas was also a risk cited by four more participants.

I found a lot of my photos in another account, and they pretend that these photos are their own. I told them that I can sue them we now have the Anti-Cyber Crime Law. They respond and delete my photos from their account. (P13)

The participants $(n=11)$ mentioned that it is essential to be active and have your profile up-to-date by posting (posts and stories (photos and videos)) regularly, having competitions, answering questions and advertising their accounts. The posts and stories also can have a positive effect on consumer trust. Twelve participants believed that the photos could have an effect on consumer trust and intention to buy. They said that pictures should not be changed a lot with Photoshop and it is better to retain their originality. Four participants reported that posting photos that were taken by customers convince others to trust them, since these serve as testimonies. They will feel that this account is active and the people buying from them are happy. Because if they were not pleased, they would not take a photo of it and send it to the seller. When people send me a photo of the product, I put it in my profile to show it to the people so they can trust that it is real. (P3)

Moreover, two participants run competitions or ask questions to encourage customers to be active and engage socially. This helps them to be known by others and to show that their account is active, which enhances trust. Sometimes, I put a post with a question, in order that I get some social engagement by having them answer the questions in the comments. (P15)

\subsubsection{Advertisement}

Sellers commonly tried to increase account activity through advertising. Fifteen participants use hashtags because they believe it can help them reach more people. They believed that they can increase the number of likes and views by using Hashtags as well as the number of followers. I use hashtags that are related to my business, such as perfumes and incense, as well as some known hashtags, which attract potential consumers to view my profile after seeing my post in the hashtags and they may follow me when they like my profile.(P2). However, sellers also reported difficulty in relation to hashtags used with pictures because there were many unrelated pictures. Searching on Instagram is difficult as many people use irrelevant hashtags under their photos. (P3)

The sellers reported that social media influencers have a massive impact on consumers trust, but they are expensive. They know that people now follow these influencers and may like to follow and buy from the sellers who they advertise.

$I$ advertise my account in a snapchat account, and then a lot of people know me from them. (P15)

There are some accounts which advertise for free or for exchanging advertisements, in which they both advertise for each other. One of the participants (P1) said that she tried to be known 
by writing comments under influencers' posts. She thought people may read her comments, and check her profile.

Participants believed that tag helped more in advertising and being known. It is mostly used between service providers and sellers, or when influencers advertise for them. For example, if there is an event with an Instagram account, they will post a picture of the seller with a tag. Sometimes if photographers take a photo of seller products, they both tag each other, which works as an exchange advertisement. They received direct messages from other entrepreneurs to ask them to advertise their accounts. Sometimes people mention their friends under my posts; it makes me happy because I believe that people mention each other under the posts that they like. (P5)

Four participants used the advertisement on Instagram, which is a new feature if an account is a business account. This way, you can advertise by paying a certain amount of money. However, there are four more participants who have business accounts but did not use Instagram advertisements because they are new, or do not know how to do it, or think they do not need it currently. They believe that the business account is helping them to be recognised by giving an insight into the followers, the interactions with their posts and stories and showing them which photos are being saved. This could help them understand what people liked more, even if they did not click 'like'. Two participants reported that one needs to have a public account to convert an account to a business. Therefore, one of them made it public, while the other did not. Now with the business account. It is straightforward. You can see the number of people who view your profile. You can promote your products on Instagram and Facebook. It is perfect and helping me a lot. It is a better way of advertising with influencers. (P14)

\subsubsection{Interpersonal interactions}

Establishing interpersonal interactions is also a factor affecting consumer trust. Participants stated that they received orders by direct messages, whereafter they sought more details from customers, such as their phone number and address with the order. A message was sent to the customer asking for the requisite information, which the latter should copy and fill in with their data. After we agreed on the products, I sent a message asking for buyer's name, mobile number, and the district name (neighbourhood name) if it was from Riyadh.(P12)

All the participants agreed that they received a lot of direct messages seeking more details, such as delivery, payment methods and prices. Nine participants had posted all the details consumers may need. However, eight of them indicated that they received many questions, the answers to which are in their profiles. They indicated that consumers may seek to ensure the availability of the product. In addition, direct communication between sellers and buyers increased mutual trust. When the sellers and buyers communicated, they are able to gauge the trustworthiness and whether they feel comfortable doing business together. Also, the response time may have an effect on trust. When we talk about using direct messages in WhatsApp, this enhances the trust between us and may encourage them to buy the product or service.(P16)
Participants (13) felt it difficult to deal with some people, especially when dealing with a variety of them with different backgrounds and genders. They believed that one should be patient and answer questions, even if answers are already available. Additionally, it is difficult to answer questions at the same time, and consumers may get frustrated by delayed responses. It is difficult to be always online, up-to-date and answering consumers' questions immediately.(P17)

Participants indicated having received positive direct messages reviewing a product (feedback). Buyers send them messages thanking them and sometimes a picture of the product taken by buyers. Some of the participants felt that the buyers' feedback enhances trust. Therefore, they take screenshots of these messages and post them, along with the pictures taken by customers. They believe that this helps them gain other consumers' trust and reflect inflow of orders and activeness of the account. I took screenshots of the direct messages from my customers and posted them. (P5). They were aware that some people might consider them to be fake messages, but felt this to be the only way to show customer reviews. Some participants prefer to add the customer screenshots to the stories instead of posting them in order to maintain an organised profile. While four participants expressed reservations about posting private messages between posts believing this would not be to the customers' liking, they may post the photos taken by consumers. I do not like to post screenshots of the direct messages as I feel that I have an organised profile and if I added these pictures, it would not look neat and organised, as it is not a picture of my products. (P8)

\subsubsection{Maroof}

All the participants knew about Maroof; however, seven were not registered with Maroof, as they did not know how to register, did not have time to do so, forgot paying fees, or got an error message when they tried to sign-up. I once tried to register, but I got an error message, I am going to try again because it would be really good for me, especially if I am going to develop my business and open a store. (P15)

Participants believed that while Maroof helped them gain consumer trust, it did not help them to be known, as Maroof is not popular. Some participants indicated having requested their customers to post reviews in Maroof, which the consumers were happy to do. However, they faced some difficulties in registering and adding comments.

\subsubsection{Payment and delivery}

Participants also felt that the payment method and delivery could enhance trust. People still trust cash on delivery as they can check the product before paying. Further, their confidence is increased if they can pick up their order (which would reveal the seller's address). To gain my customer trust I gave them my house location and my mobile number. (P5)

\subsubsection{Events, exhibitions and physical stores}

There are also additional social media applications such as Snapchat and Twitter that participants use, mostly when they want to cover an event or to advertise their product.

Participants confirmed participating in events and exhibitions. One of these exhibitions is Montijoon, which is free and provided 
by the government to help entrepreneurs. They feel that people know them more from these events and can trust them more, because they can touch and feel products, and also try them sometimes. During the event, they hand visitors their business cards that include their shop name, social media accounts and contact details. Sometimes, they also distribute a few free samples, which encourages customers to trust them. I attended an event, and gave free samples to try or take home. I feel that people loved them. During the seven day event, I gave people my contact and social media details. (P14)

Additionally, a few participants indicated having placed their products in physical stores. However, one of the participants said that she did not benefit from that in any way, attributing it to the product placement not being proper, she being helpless to change the organisation of the store since it was not hers.

Two participants sponsored small events such as a graduation event in a school with small gifts from their products. This worked as an advertisement for them and helped in more people trusting them, having tried their products. To gain trust and to be known, we sometimes sponsor events, which cannot afford gifts. We provide the gifts from our products. (P13)

\subsubsection{E-commerce platforms}

Six participants stated that they are registered in e-commerce platforms, and e-commerce solutions for home-based businesses (one of them is provided free by the government). They think it may help to be known when someone searches on these platforms for a specific category. However, they do not believe it is beneficial, not having received many orders through it; they receive it more through social media. Therefore, they are not active on these e-commerce platforms. Other participants did not know about these platforms or think they should pay for using them. They preferred to have just the social media accounts for their business, as these are free and widely-used. I did not register in any e-commerce platform, but I knew that the government provide some services for free such as the platform and Maroof, but I need to ask more about them and to know how to register to gain consumer trust. (P4)

One of the participants felt it convenient to use these platforms, having received orders in a more organised way, with the customers usually paying the full amount with the order, which means that they trust these platforms more than just the social media. If the order is done through the platform, I receive the payment directly by money transfer; they also provide a delivery: I just receive the list of orders and pack them to be delivered. (P1)

While one of the participants had her own website, the rest did not, considering it difficult or expensive to build one, feeling further that it might not be helpful in reaching out to customers. However, the participant with the website revealed her experience to be good, having received the orders, with the website being tidy, organized and clear, enabling customers to find all products with their prices. However, she still receives orders and questions by WhatsApp and is still active on Instagram, though she knows not why some people do not want to order from the website, preferring to place orders directly by messages. I put all the details and prices on the website, but on Instagram, I just posted some photos. However, some people do not want to order via the website. Instated they send me orders by WhatsApp. Both are ok for me. But it is easier to receive orders by the website compared to WhatsApp where I need to look again and again and ask the customers to be sure that I am not sending something wrong. So, the site is more comfortable because I receive the orders in a table. (P9)

\section{Discussion}

This study aims to understand how sellers use social networks as commercial platforms, even with a lack of traditional commercial functions. Our findings show that sellers are attracted to the use of social media for their business, because it is free, easy, and effective. These results match a previous study focussing on Facebook use [40]. However, the social commerce platform in Saudi Arabia mostly used for businesses as a shop window is Instagram, considered to be a picture-videos-based social commerce platform. This research describes how the design of social media supports sellers' activities, but sometimes fails to yield them the full potential. In this discussion, we will explore how we could better design a social commerce platform.

Social media applications impact the labour market by enabling female Saudi entrepreneurs to trade and provide products and services. These applications empower them to have their own business and to deal directly with their consumers. Moreover, the culture in Saudi Arabia has started to change due to the government's 2030 vision as discussed in the introduction. Research has shown that the culture may change and influence political changes, which also may reflect on economic and purchase behaviours [41]. These changes in culture, with the availability of social media applications, create opportunities for female sellers in Saudi Arabia to represent themselves. Compared to a previous study, which found Saudi females having issues relating to some of the administrative procedures because a male is required to do them [10], it can be seen that the changes are reflecting not just in purchasing behaviour, but also in the selling behaviour. These issues do not exist any more due to the availability of online systems and government support for females to participate in an event, to help them to be known and trusted. For example, we have found that females can register on the free Maroof certification service online.

Social media create opportunities for sellers [32] not just as an income source, but also to enhance their self-esteem. Our participants have indicated that they improve their products based on the comments from direct messages. Further, sometimes they ask their customers to help them in choosing or designing their products. This is also revealed in previous studies, where small businesses benefited from social media, the two-way information between sellers and buyers, in different ways such as attracting customers [22] and improving or designing their products [32][23].

Our findings revealed that the way consumers know the sellers affects trust. For example, if consumers know sellers through their family and friends, they will feel confident to buying from them. The family and friends for both sellers and previous customers have a significant role in being known and trusted on social 
commerce platforms. Table 2 summarises sellers' activities on social media networks.

Table 2 A summary of sellers' activities on social media networks

\begin{tabular}{|l|l|}
\hline Goal & Activity \\
\hline $\begin{array}{l}\text { Reaching } \\
\text { potential } \\
\text { customers }\end{array}$ & $\begin{array}{l}\text { Using hashtags } \\
\text { Following consumers } \\
\text { Writing comments under influencers' posts } \\
\text { Sponsoring }\end{array}$ \\
\hline $\begin{array}{l}\text { Self- } \\
\text { presentation }\end{array}$ & $\begin{array}{l}\text { Profile/ post/ stories/ interact with followers by } \\
\text { direct messages/ using other social networks }\end{array}$ \\
\hline Gaining trust & $\begin{array}{l}\text { Registering with Maroof } \\
\text { Participating in events and physical stores } \\
\text { Professional Self-presentation } \\
\text { Posting customers' photos and feedback } \\
\text { Registering in e-commerce platforms } \\
\text { Posting their training certificate } \\
\text { Family and friends (previous customers) } \\
\text { Cash on delivery }\end{array}$ \\
\hline
\end{tabular}

Our study shows that sellers try to have both online and offline social presence, considering it to enhance trust. Previous studies found that social presence can affect consumers' trust and their purchase intention [16]. For online social presence, the use of social media is one of the tools that can create trust, which is also revealed in previous studies [17][20], and with more information in their profile, they become more trustworthy [37]. Participants use these tools as a shop-presentation to present information about the status info which is mostly in their profile, direct messages, and graphical presentation as cited by [17]. They were also actively using Hashtag '\#' functions, compared to being tagged or using mention technology '@’ to be known.

According to warranting theory, the cues that are more difficult to manipulate are more trusted information [48] [44]. Our study found that participants believed that the number of followers could affect consumer trust, which is difficult to manipulate. Also, their membership in Maroof cannot be manipulated and enhanced trust, especially since Maroof is considered as a third-party trusting mechanism. Participants present some information that can be manipulated, but they still think it can be effective. Thirdparty mechanism is considered as an uncertainty-reducing mechanism, enhancing trust between the seller and the consumer [30].

Our study revealed that the number of followers helps sellers to gain trust- higher numbers indicate greater trustworthiness. A previous study measured the success of a seller based on the followers' number [11]. To increase the number of followers, participants tend to use hashtags and advertisements, which was also shown by a previous study, which promoted on Twitter and found it to increase the followers' number [36]. Additionally, participants try to have an active account with social interaction. Social engagement helps to have more followers [51]. Direct communication between our participants and their consumers can enhance trust between them. The use of social media and communities increases social capital by having a communication network [17].
The results of our studies showed that sellers were trying to build their reputation online and offline. They create their way to present the reviews of the customers by posting screenshots of their customers' comments. Previous studies represented the role of the reputation system in enhancing trust by using rating and feedback from their customers [26]. Even with the absence of the reputation system in social media applications, sellers found a way to show the feedback that they received from their consumers by posting screenshots of the direct messages, to help them gain consumers' trust.

Our study found that one of the reasons to have a social commerce platform is self-esteem. This finding supports the previous studies, which found that social relationship can affect behaviour and thoughts [28] and that it enhances self-esteem [22]. It also improves the relationship quality which impacts on customers loyalty [34], as our study revealed.

Instagram, as mentioned by some of our participants, has started converting itself to the business side. Other studies revealed how Instagram and Facebook have begun to insert advertising on their platforms[50]. Our findings represented that this may help them to become popular. Sellers believed that these advertisements just let people know about their account, but will not affect their trust. However, a previous study showed that customers would trust advertisement information based on their belief in social network applications [50]. This feature exists also in Facebook, which offers advertisement services [23]. Further, our findings indicated that sellers exchange social ads, where each one advertises for others by posting a photo with a tag. This helps them to deliver the ads to the target group. One of the mechanisms that our sellers use is the different payment methods (mostly cash on delivery). This method is mostly chosen when the sellers are Micro, Small and Medium Enterprises[47]. Our participants believed that consumers prefer cash on delivery, which is also the case in Indonesia and Turkey[49][47].

\section{Recommendations}

Some entrepreneurs shared their businesses with their family or friends. Therefore, it is recommended to include features that support the management of an account by different users. Another issue was that Instagram has many unrelated posts under hashtags, a solution to which could be banning the account if a warning is ignored. Moreover, tagging a photo will not be presented to the public if the user's account is private. It is recommended to give the users the options to choose which posts will be made private and which would be made public, as our study shows that some buyers want to show the post with the tag, but do not want to share their whole profile and posts.

Friends and family have a significant role in the issue of trust and gaining a wider reach. Therefore, adding features showing friends' favourites and purchases, keeping in mind the privacy aspect, by giving consumers a choice to make their purchase activities public or to keep them private, may help consumers, as they trust their friends and may follow their opinion and recommendations [18]. Additionally, adding a public wish list to 
the buyer's account may have an effect on trust and increase sales, as can be seen from Airbnb [31].

Integrating social commerce with the marketplace enhances trust as well as customer satisfaction [46]. Our findings present the importance of having socially interactive e-commerce platforms. Trust creation features are essential in designing social commerce. Therefore, some features that should be implemented or retained, such as the number of followers, likes, views, tags and mentions need to be enhanced. Additionally, social media applications should implement a reputation system to show the customer rating and feedback. However, there is a need for reward systems to encourage these interactions; for example, when they post a photo or write feedback, they may score more in public or get rewards. E-Bay uses a reward system that enables consumers to earn points or special offers, which they can use to pay for a product [18]. Moreover, some companies use reward systems for consumers who leave feedback, whether or not it was positive [35]. Also, some companies use the reward systems when their consumers refer them to their friends or family members [21].

More data that cannot be manipulated include the number of verified purchases, etc. It is also recommended to post feedback to show the 'verified buyers' [9]. Further, presenting trade history and positive trade percentage are recommended to enhance trust, as also supported by a previous study [12]. Showing past customer activities, such as features showing the 'Customers Who Bought This Also Bought', which is available in Amazon, help consumers to find relevant purchases [18].

Certification services like Maroof have potential benefits to both sellers and buyers. However, they should be integrated with the social media applications to be more usable. Besides, social commerce platforms should include a verified system for trusted sellers' accounts. Finally, it was clear that there is a need for both online orders and text-based orders. The online orders will help sellers to have a more organised list of the received orders. The text-based orders help sellers to receive the order from the people who do not trust placing order automatically and from those who would feel more confident after their direct communication with the seller.

\section{Conclusion and Future work}

This study has provided an overview of Saudi entrepreneurs' behaviours and activities in social commerce. It explored how they sell and market their products using social media platforms such as Instagram and WhatsApp as well as using offline tools such as family and friends recommendations and events. Our results suggest that entrepreneurs make effective use of existing social media platform features in order to market themselves and build their reputation to gain consumer trust. However, social media platforms could be more efficient and effective. We believe that our results and recommendations provide a starting point for future research. Important items for future research include carrying out experiments to test the implementation of social commerce functionality discussed in the Recommendations Section. It is also essential to examine how implemented recommended features impact trust between buyers and sellers.

\section{REFERENCES}

[1] Alfarez Abdul-Rahman and Stephen Hailes. 2000. Supporting Trust in Virtual Communities. Hawaii International Conference on System Sciences (2000), 1-9.

[2] Norah Abokhodair and Sarah Vieweg. 2016. Privacy \& Social Media in the Context of the Arab Gulf. Designing Interactive Systems (2016), 672-683.

[3] Mohammad bin Salman bin Abdulaziz Al-Saud. 2030 Vision. Retrieved August 20, 2018 from http://vision2030.gov.sa/en

[4] Youcef Baghdadi. 2013. From E-commerce to social commerce: A framework to guide enabling cloud computing. fournal of Theoretical and Applied Electronic Commerce Research 8, 3 (2013), 12-38.

[5] Kathy Baxter. 2015. Understanding Your Users A Practical Guide to User Research Methods.

[6] Izak Benbasat, David K Goldstein, and Melissa Mead. 1987. The Case Research Strategy in Studies of Information Systems. MIS Quarterly 11, 3 (1987), 369-386. DOI:https://doi.org/10.2307/248684

[7] Virginia Braun and Victoria Clarke. 2006. Using thematic analysis in psychology. Qualitative Research in Psychology 3, 2 (2006), 77-101.

[8] Vineeta Chaube, Andrea L. Kavanaugh, and Manuel A. Pérez-Quiñones. 2010. Leveraging social networks to embed trust in rideshare programs. Hawaii International Conference on System Sciences (2010), 1-8.

[9] Renata Gonçalves Curty, Ping Zhang, Hinds Hall, Hinds Hall, and Ping Zhang. 2011. Social Commerce: Looking Back and Forward. 2007, (2011), $1-10$.

[10] Abeer Yousuf Danish and Helen Lawton Smith. 2012. Female entrepreneurship in Saudi Arabia: opportunities and challenges. International fournal of Gender and Entrepreneurship 4, 3 (2012), 216-235.

[11] Humaira Dar and Asadullah Shah. 2013. A 10 C's of social networking, interconnections and the impact on social networking. International Conference on Information and Communication Technology for the Muslim World (2013).

[12] Hayley I Evans, Marisol Wong-Villacres, Daniel Castro, Eric Gilbert, Rosa I Arriaga, Michaelanne Dye, and Amy Bruckman. 2018. Facebook in Venezuela: Understanding Solidarity Economies in Low-Trust Environments. Conference on Human Factors in Computing Systems (2018), $1-12$.

[13] Facebook Business. 2014. New for Facebook Pages: Calls to Action. 1-2. Retrieved from https://www.facebook.com/business/news/call-to-actionbutton

[14] Toni Ferro. 2015. The Importance of Publicly Available Social Networking Sites (SNSs) to Entrepreneurs. Proceedings of the 18th ACM Conference on Computer Supported Cooperative Work \& Social Computing - CSCW '15 (2015), 917-928.

[15] Katie Finley. 2012. Trust in the Sharing Economy: An Exploratory Study. (2012).

[16] David Gefen and Detmar Straub. 2003. Managing User Trust in B2C eServices. e-Service fournal 2, 2 (2003), 7-24.

[17] Ali Gheitasy, José Abdelnour-Nocera, and Bonnie Nardi. 2015. Sociotechnical gaps in online collaborative consumption (OCC): An example of the Etsy community. Proceedings of the 33rd Annual International Conference on the Design of Communication - SIGDOC '15 (2015), 1-9.

[18] Renata Gonçalves Curty and Ping Zhang. 2013. Website features that gave rise to social commerce: A historical analysis. Electronic Commerce Research and Applications 12, 4 (2013), 260-279.

[19] Qais Hammouri. 2017. The Antecedents of Trust in Social Commerce. (2017), 648-652.

[20] Qais Hammouri and Emad Abu-Shanab. 2017. The antecedents of trust in social commerce. ICIT 2017 - 8th International Conference on Information Technology, Proceedings (2017), 648-652.

[21] Hui Han and Silvana Trimi. 2017. Social commerce design: A framework and application. Journal of Theoretical and Applied Electronic Commerce Research 12, 3 (2017), 50-68.

[22] Syahida Hassan, Janet Toland, and Mary Tate. 2016. From Blogosphere to Social Commerce: A Laddering Analysis of Sellers' Motivation. In Hawaii International Conference on System Sciences, 2146-2155.

[23] Zhao Huang and Morad Benyoucef. 2013. From e-commerce to social commerce: A close look at design features. Electronic Commerce Research and Applications 12, 4 (2013), 246-259.

[24] Master Informatics. 2016. From E-commerce to She-commerce: The rise of She-era? (2016).

[25] Instagram. 2018. Advertising on Instagram | Instagram for Business. Instagram 1, 1-9. Retrieved February 1, 2018 from https://business.instagram.com/advertising/

[26] Audun Jøsang, Roslan Ismail, and Colin Boyd. 2007. A survey of trust and reputation systems for online service provision. Decision Support Systems 43, 2 (2007), 618-644.

[27] Rohayah Kahar, Faizal Yamimi, Ghazali Bunari, and Hadina Habil. 2012. 
Trusting the Social Media in Small Business. Procedia - Social and Behavioral Sciences 66, 0 (2012), 564-570.

[28] Brian Lakey and Sheldon Cohen. 2000. Social Support Theory and Measurement. In Social Support Measurement and Intervention.

[29] Airi Lampinen and Barry Brown. 2017. Market Design for HCI: Successes and Failures of Peer-to-Peer Exchange Platforms. CHI Conference on Human Factors in Computing Systems. ACM (2017), 4331-4343.

[30] Airi Lampinen and Coye Cheshire. 2016. Hosting via Airbnb: Motivations and Financial Assurances in Monetized Network Hospitality. Conference on Human Factors in Computing Systems (2016), 1669-1680.

[31] Donghun Lee, Woochang Hyun, Jeongwoo Ryu, Woo Jung Lee, Wonjong Rhee, and Bongwon Suh. 2015. An Analysis of Social Features Associated with Room Sales of Airbnb. ACM Conference Companion on Computer Supported Cooperative Work \& Social Computing (2015), 219-222.

[32] Sang Heui Lee, David DeWester, and So Ra Park. 2008. Web 2.0 and opportunities for small businesses. Service Business 2, 4 (2008), 335-345

[33] Chia-Ying Ying Li and Yi-Cheng Cheng Ku. 2017. The Power of a ThumbsUp: Will E-commerce Switch to Social Commerce? Information \& Management 55, 129 (2017), 0-1.

[34] Ting-Peng Liang, Yi-Ting Ho, Yu-Wen Li, and Efraim Turban. 2011. What Drives Social Commerce: The Role of Social Support and Relationship Quality. International fournal of Electronic Commerce 16, 2 (2011), 69-90.

[35] Libo Liu, Choon Ling Sia, Huaping Chen, and Jinbi Yang. 2013. Sellers versus buyers: differences in user information sharing on socia commerce sites. Information Technology \& People 29, 2 (2013), 444-470.

[36] Yi Liu and Bernadetta Tarigan. 2016. Effects of promotion tweets on the number of followers in micro-blogging site. International Conference on Electronic Commerce e-Commerce in Smart connected World (2016), 1-8.

[37] Xiao Ma, Jeffery T. Hancock, Kenneth Lim Mingjie, and Mor Naaman 2017. Self-Disclosure and Perceived Trustworthiness of Airbnb Host Profiles. Proceedings of the 2017 ACM Conference on Computer Supported Cooperative Work and Social Computing - CSCW'17 (2017), 2397-2409.

[38] Carolanne Mangles. 2017. How businesses use social media: 2017 report. Smart Insight, 1-11.

[39] Ministry of Commorce and Investment. 2018. About us. Maroof. Retrieved September 1, 2018 from https://maroof.sa/Home/About

[40] Carol Moser, Paul Resnick, and Schoenebeck Schoenebeck. 2017. Community Commerce: Facilitating Trust in Mom-to-Mom Sale Groups on Facebook. Conference on Human Factors in Computing Systems (2017).

[41] Celeste See Pui Ng. 2013. Intention to purchase on social commerce websites across cultures: A cross-regional study. Information and Management 50, 8 (2013), 609-620.

[42] Stina Nylander and Åsa Rudström. 2009. Questions, inspiration, feedback and contributions: How entrepreneurs network online. Communities \& Technologies July (2009), 128-137.

[43] Johnny Saldaña. 2016. The Coding Manual for Qualitative Researchers. SAGE Publication.

[44] W Scott Sanders. 2016. Testing the Application of Warranting Theory to Online Third Party Marketplaces: The Effects of Information Uniqueness and Product Type. International Conference on Social Media \& Society (2016), 1-7.

[45] Wannapon Suraworachet, Sarawadee Premsiri, and Nagul Cooharojananone. 2012. The study on the effect of Facebook's socia network features toward intention to buy on F-Commerce in Thailand. In International Symposium on Applications and the Internet, 245-250.

[46] Gayatri Swamynathan, Christo Wilson, Bryce Boe, Kevin Almeroth, and Ben Y Zhao. 2008. Do Social Networks Improve e-Commerce? A Study on Social Marketplaces. Proceedings of the First Workshop on Online Social Networks 1, (2008), 1-6.

[47] Ahmad Anshorimuslim Syuhada and Windy Gambetta. 2013. Online Marketplace for Indonesian Micro Small and Medium Enterprises Based on Social Media ScienceDirect. Procedia Technology 11, 11 (2013), 446-454

[48] J B Walther and M R Parks. 2002. Cues filtered out, cues filtered in: Computer-mediated communication and relationships. Handbook of Interpersonal Communication August (2002), 529-563.

[49] Seda Yoldas. 2012. A Research about Buying Behaviours of Online Customers, Comparison of Turkey with UK. (2012).

[50] JennyXinyan Zhang and Rachael K.F. Ip. 2015. E-Commerce Advertising in Social Networking Sites and Implications for Social Commerce. Proceedings of Pacific Asia Conference on Information Systems June (2015), $1-10$.

[51] Ermira Zifla and Sunil Wattal. 2016. Community Engagement In Peer-ToPeer Business: Evidence From Etsy.com. European Conference on Information Systems (2016).

[52] 2019. More Than 1000 female apply to participate in Montijoon 5. Riyadh chamber, 1-6. Retrieved December 1, 2018 from https://www.chamber.sa/MediaCenter/News/Pages/03122017montjoon.a $\operatorname{spx}$ 